\title{
AS NOVAS CONFIGURAÇÕES IDENTITÁRIAS E SEUS EFEITOS DE SENTIDO NA MÍDIA BRASILEIRA
}

\author{
Edjane Gomes de Assis ${ }^{*}$ \\ Universidade Federal da Paraíba \\ Centro de Ciências Humanas, Letras e Artes \\ Departamento de Letras Clássicas e Vernáculas \\ João Pessoa, PB, Brasil
}

\begin{abstract}
Resumo: Com base na Análise de Discurso francesa, sobretudo na esteira de Pêcheux (2006), Foucault (2000; 2002; 2005), Charaudeau (2006), e em diálogo com a Análise Dialógica do Discurso (BAKHTIN, 2000), com as reflexões sociológicas de Bauman (2005), e estabelecendo articulação com a Teoria da Comunicação (MORETZSOHN, 2012), nosso estudo investiga como os discursos atuais sobre a reafirmação da identidade nacional e suas novas configurações ressurgem na mídia brasileira através de mecanismos disciplinares. Para tanto, analisamos duas campanhas publicitárias das empresas Chevrolet e Skol, ambas veiculadas em março de 2017. Compreendendo o texto publicitário como uma materialidade discursiva, em que estão imbricados elementos sociais, históricos e ideológicos, evidenciamos que as campanhas, para se (re)afirmarem perante a sociedade, recuperam o discurso da democratização advindo das novas demandas sociais, mas em sua interdiscursividade prevalece a ideia da autopromoção, cujo objetivo maior é o lucro. Assumem, assim, posicionamentos característicos de uma sociedade capitalista e competitiva.
\end{abstract}

Palavras-chave: Discurso. Identidade. Mídia brasileira.

\section{DISCUSSÃO PRELIMINAR}

"O novo não está no que é dito, mas no acontecimento de sua volta" (FOUCAULT, 2000, p. 217). As palavras de Foucault nos convidam para a reflexão de que, enquanto sujeitos sociais, estamos constantemente reproduzindo as ideias do outro, mas sempre imaginando sermos "donos" de nosso dizer. Tal estratégia é o que nos torna autores, ou seja, assumimos uma função dentro de práticas discursivas determinadas. Este pensamento dialoga com a afirmação de Bakhtin (2000, p. 291), quando observa que "todo enunciado é um elo da cadeia muito complexa de outros enunciados".

Nos últimos tempos, em função das novas transformações sociais promovidas pelo movimento das minorias (mulheres, negros, índios, homossexuais, dentre outros sujeitos silenciados e reprimidos ao longo da história), observamos um novo processo de reconstrução discursiva, moldado por vozes que buscam resistir aos modos disciplinares que docilizavam os corpos através de tortura, tirania e opressão. A história está constituída de episódios e conquistas que, em seus bastidores, em espaços quase imperceptíveis aos olhos humanos, cultivam a dor, a violência, a repressão.

\footnotetext{
*Professora Doutora em Linguística. E-mail: assisedjane@ hotmail.com.
} 
As práticas de dominação sobre os sujeitos silenciados perduraram por longos períodos da história, mas ainda continuam em outras materialidades e com técnicas mais refinadas. Na idade Média - dominada pelo regime da Inquisição - observamos uma higienização da sociedade através da sentença dada aos sujeitos que não se enquadravam nos princípios difundidos pela Igreja. E bem mais tarde chegamos ao século XX e nos deparamos com grandes guerras mundiais, como a Segunda Guerra Mundial (1939-1945), que teve como figura central o ditador alemão Adolf Hitler e sua política de genocídio. São inúmeras ações, cada uma com seus dispositivos e mecanismos de poder próprios de sua época, que só funcionavam porque estavam em sintonia com a legislação vigente, por mais estranho que isto possa nos parecer. A dor e a tortura eram perfeitamente justificadas e serviam de lição para os "transgressores".

Ainda no século XX, mais especificamente na segunda metade da década de 1960 (fase mais ácida dos anos sessenta), a sociedade vivencia uma série de acontecimentos determinantes, resultando em várias conquistas que adquirem notoriedade neste século XXI. O "maio de 68 francês", a luta pela igualdade racial nos Estados Unidos, dentre outros movimentos, atestam que nós, enquanto sujeitos históricos, também constituímos poder através da resistência, pois o poder circula, e onde "onde há poder, há resistência" (FOUCAULT, 2000, p. 10). Os movimentos de luta pela igualdade de direitos promovidos pelo movimento feminista, o levante revolucionário dos estudantes e trabalhadores que reivindicam melhorias em vários setores, e, ainda, as novas concepções identitárias e suas formas de representação, comprovam que as resistências são fundamentais para o estabelecimento da uma nova democratização social.

No Brasil, os procedimentos de resistência geraram resultados mais significativos quando incorporados/materializados em leis (no aparato jurídico), que têm o objetivo de resguardar e assegurar os direitos do cidadão e da cidadã e o bem-estar social, pois "o discurso está na ordem das leis" (FOUCAULT, 2000, p.7). Eis algumas destas conquistas transfiguradas em leis: Estatuto da Criança e do Adolescente (Lei n ${ }^{\circ}$ 8.069/90), Estatuto do Idoso (Lei $\mathrm{n}^{\circ}$ 10.741/03), Lei Maria da Penha (Lei $\mathrm{n}^{\circ} 11.340 / 06$ ), entre outras medidas que primam pela qualidade da sociedade. Contudo, mesmo que ainda não vislumbremos saldos positivos, sobretudo em diminuir os casos de violência contra a mulher, o discurso jurídico, um construto de leis, contribui para a solidificação das lutas por direitos que devem ser respeitados, diferentemente das práticas disciplinares que estavam amparadas na lei para justificar a dor e a desigualdade social que perduraram durante séculos.

Tais discussões preliminares são necessárias para que possamos ver e entrever como os mecanismos de resistência (demarcados nas lutas pelos direitos civis) reaparecem agora, em 2017, em um novo acontecimento - no discurso midiático. Com base na Análise do Discurso francesa (AD), objetivamos analisar como a mídia, sobretudo o dizer publicitário de duas peças produzidas pela Chevrolet e pela Skol, em busca de (re)afirmar um lugar e posição na sociedade, utilizam, em suas materialidades discursivas, enunciados que (re)criam efeitos de sentido advindos das demandas atuais, das lutas dos sujeitos por espaços que lhes foram negados, silenciados e controlados ao longo da história.

Sistematizamos nossa análise em alguns momentos que se coadunam: no primeiro momento recuperamos as bases teóricas da AD, a partir de Pêcheux (2006), Foucault 
(2000; 2002; e 2005) e Charaudeau (2006). Dialogamos com alguns conceitos da Análise Dialógica do Discurso, com base em Bakhtin (2000), percorremos um caminho traçado por Bauman (2005) a fim de entender como se processa o que ele chama de "liquidez social", e discutimos, também, a questão da velocidade midiática com base no pensamento de Moretzsohn (2012). No segundo momento, fazemos uma discussão sobre os dispositivos da mídia enquanto aparelho disciplinar e regulador. E no terceiro momento analisamos nosso corpus, que é composto de duas peças publicitárias, da Chevrolet e da Skol, ambas veiculadas na versão online em 2017. O afinamento das categorias teóricas - acontecimento midiático, poder e resistência - com o corpus do trabalho (peças publicitárias) nos possibilitou reconhecer que as estratégias utilizadas pela mídia, revestidas do discurso da atualidade, funcionam como uma forma de autopromoção das empresas, cujo objetivo consiste, fundamentalmente, em gerar o aumento de vendas.

\section{SUJEITO, PODER E RESISTÊNCIA}

Os estudos linguísticos passaram por um longo processo de reconfigurações epistemológicas que contribuíram para um nova concepção de língua e linguagem. Ainda com base na linguística histórico-comparativa (que vigorou até o século XIX) e caminhando para a Linguística de Saussure (Século XX), os postuladores científicos, de base estruturalista, silenciaram o sujeito e seus processos enunciativos. Os primeiros rumores sobre a mudança de ponto de vista em relação ao objeto (sujeito da comunicação) são visualizados por Benveniste com sua teoria da enunciação e análise das relações intersubjetivas.

Todavia, somente no final da década de 1950 e nos primeiros anos da década de 1960, com a guinada pragmática dos estudos linguísticos, as ideias do funcionalismo linguístico (em detrimento de formalismo pautado apenas na estrutura sintagmática), são amplamente difundidas através das novas tendências advindas da Linguística, ciênciapiloto. Eis algumas teorias: a Linguística Textual, a Sociolinguística, a Análise da Conversação, a Etnolinguística, a Pragmática, a Análise do Discurso (em suas várias vertentes) e outras tendências que passam a tratar a língua/linguagem dentro dos contextos de uso. A língua passa, assim, a ser explicada com base em elementos sociológicos, psicológicos, históricos, antropológicos que são movidos/recuperados para a investigação dos sentidos materializados no linguístico.

No interior das bases funcionalistas, adentramos o território das teorias do discurso. Focalizamos nosso olhar para a Análise do Discurso francesa (AD), que trata o sujeito da comunicação como um sujeito discursivo, constituído por uma historicidade. Com base na "tríplice aliança", formada por três grandes áreas do conhecimento - Linguística, História e Psicanálise -, a AD observa o sujeito e seu discurso como o resultado de elementos sociais, históricos e ideológicos. Para entender como os enunciados promovem sentido, é necessário observar os lugares, as circunstâncias e a vontade de verdade destes sujeitos. Se faz necessário, ainda, analisar os dispositivos utilizados para demarcar suas posições na sociedade e (re)afirmar identidades. O sujeito, em AD, se diferencia do sujeito da Psicanálise porque não o enxerga mais como um indivíduo somente clivado e 
censurado; nem seria somente o sujeito da história, do marxismo em sua primeira fase, porque não é mais um sujeito totalmente assujeitado, ou seja, sem possibilidade de resistência e interpelado pela ideologia do Estado. É agora, um sujeito discursivo, social, com possibilidades de resistência, e ocupa várias funções nos espaços sociais. $\mathrm{O}$ sujeito discursivo é uma junção de todos esses sujeitos que vão aparecer através do discurso mediante dispositivos de poder.

Ao estudar o poder, Foucault revela que seu objetivo, na verdade, seria estudar o sujeito e seu comportamento no campo social e disciplinar. Em Hermenêutica do sujeito - curso ministrado em 1982 - o filósofo estabelece uma comparação do sujeito tratado por Platão, Epicuro, Sêneca, com o sujeito moderno e sua inserção na política. Em sua investigação sobre as técnicas de subjetivação como o "cuidado de si", ele mostra como a sociedade, mediante técnicas disciplinares, vai moldando e docilizando os corpos em busca de materializar verdades que não passam de um jogo de representação. Em sua fase sobre a genealogia do poder ele observa que se faz necessário um redimensionamento desse sujeito tradicional:

\footnotetext{
É preciso soltar, se livrar do sujeito constituinte, livrar-se do próprio sujeito, isto é, chegar a uma análise que possa dar conta da constituição do sujeito na trama histórica. É isto que eu chamaria de genealogia, isto é, uma forma de história que dê conta da constituição dos saberes, dos discursos, dos domínios de objeto, etc., sem ter que se referir a um sujeito, seja ele transcendente com relação ao campo de acontecimentos, seja perseguindo sua identidade vazia ao longo da história. (FOUCAULT, 2005, p. 7).
}

O fazer genealógico exige um contínuo movimento que se distancia do caráter linear e cronológico da história tradicional. Quando estuda o discurso sobre a loucura, ainda em sua primeira fase, Foucault observa que era necessário utilizar dispositivos (laudo pericial, técnica da escuta) que diagnosticassem um sujeito como louco, alguém desprovido de suas faculdades mentais/racionais. A loucura, no período entre 1660 e 1760, na França, funcionava como uma marca identitária para excluir os indivíduos que não se adequavam aos princípios e dogmas estabelecidos pelo poder vigente. Era necessário, então, fazer uma higienização da sociedade e separar tais sujeitos, a fim de que não contaminassem os demais - são utilizados, portanto, mecanismos de exclusão e punição. Modos aterrorizantes, que ainda aparecem na opacidade dos dizeres, continuam ecoando ao longo da história, mas por outros meios.

Sendo assim, quando se estuda o sujeito estuda-se, concomitantemente, o poder. Amplamente investigado em várias áreas do conhecimento e ao longo da história, a análise do poder cultiva as características próprias de cada pesquisador e sua área específica. A inquietação de Foucault acerca da investigação sobre o poder consistia na escassez de uma análise voltada para um processo genealógico, como ele surge mediante dispositivos disciplinares. O filósofo observa que os estudos acerca do poder comumente apareciam de modo antagônico (uma disputa entre o bem ou o mal). Tal problemática adquire uma tonalidade mais forte em suas discussões dominadas por profundos embates e rupturas com os ideais marxistas fortemente difundidos na primeira fase da Análise do Discurso pelo viés de Pêcheux. Conforme vai desenvolvendo suas pesquisas, influenciadas pelos estudos de Nietzsche, Foucault chega à conclusão de que o poder nem deve ser tratado estritamente como uma negatividade, nem deve ser conduzido de modo estático, mas circular, como um processo contínuo - é o que ele chama de "microfísica". 
O deslocamento de uma análise do poder circunscrita ao Estado para um universo significativo e corporizado em infinitos espaços (até mesmo no interior do próprio indivíduo) compreende uma atualização, e ao mesmo tempo, uma ruptura feita por Foucault em contraposição ao que se fazia naquela época, dominada pelo pensamento marxista alimentado pelo Partido Comunista Francês. Ao tratar da resistência - que seria a possibilidade de o sujeito escapar ao assujeitamento/alienação -, Foucault tenta comprovar, através de indagações típicas do saber filosófico, que a resistência também configura um dispositivo de poder. Assim, podemos entender que o sujeito, mesmo estando aparentemente impossibilitado de exercer seu direito e liberdade, ainda encontra formas de resistir, mediante diferentes ações. Os eventos registrados pela história comprovam algumas destas ações: as resistências aparecem em plena era medieval, nas civilizações que se contrapunham aos (e)feitos do Império Romano; estavam nos campos de algodão, através dos cantos dos escravos negros americanos; estavam nas vítimas do holocausto, nas memórias escritas nos mais diversos suportes e que ainda hoje são descobertas por historiadores; estão na atualidade, na liquidez de nossa sociedade que a todo momento se (re)inventa e vai adornando/moldando/formando/formatando nossa percepção sobre o mundo. É necessário, portanto, conduzir nosso olhar para algumas reflexões fundamentais: Como podemos reconhecer quem é este sujeito que fala e como ele demarca seu território frente aos acontecimentos?

$\mathrm{O}$ acontecimento, o modo como as ideologias se materializam no discurso, é estudado por especialistas de diversas áreas do conhecimento e aparece com diferentes concepções para cada pesquisador. Para os historiadores, trata-se de um acontecimento histórico, algo demarcado cronologicamente na história - as grandes batalhas, a conquista de um reino, os fatos que devem ser relatados, são vistos dentro de uma série de outros acontecimentos. Os jornalistas lidam como o acontecimento factual, com a história imediata. Os fatos surgem e devem ser documentados, ou seja, informados quase que em tempo real. Há toda uma luta pelo "furo da reportagem", a necessidade de noticiar primeiro, ainda no calor do acontecimento; o que pode resultar, na maioria das vezes, em equívocos e julgamentos apressados sobre um fato.

Já na perspectiva discursiva, o acontecimento seria uma junção do acontecimento histórico (historicidade) e do acontecimento instantâneo (fato jornalístico). Em $O$ discurso: Estrutura ou Acontecimento, Pêcheux (2006), observa que é no campo linguístico, lugar da materialização do pensamento, que podemos analisar a reprodução de dizeres demarcados, reverberados em outros lugares. Não há como dissociar a análise da estrutura sem a observação de seu acontecimento. Para tanto, ele analisa o enunciado On a gagné (Ganhamos) pronunciado pelos eleitores no acontecimento histórico - a vitória de François Mitterand à presidência da França em maio de 1981. Observa como este enunciado reaparece no discurso da imprensa, retomando novas significações, e se transformando em um acontecimento discursivo. Quando analisa a repercussão da vitória de Mitterand nos grandes jornais franceses, a partir de enunciados como François Mitterand é eleito presidente da República Francesa; A esquerda francesa leva a vitória eleitoral dos presidenciáveis; A coalização socialista-comunista se apodera da França, Pêcheux mostra que uma análise apenas estruturalista, que trata a língua como produto fechado e acabado, limita a interpretação, pois não abre espaço para entender como os ditos fazem sentido e como são evidenciados no jogo de oposições. 
Desta forma, estudar a mídia como um espaço (re)produtor de identidades é algo quase imprescindível na atual conjuntura social, tanto nacional como internacional, sobretudo neste momento de profundas confluências ideológicas.

\section{MÍDIA E (RE)CONSTRUÇÃO DO SENTIDO}

Nunca se questionou tanto as verdades materializadas no discurso midiático como neste século XXI. No Brasil, mais precisamente de 2010 para hoje, 2017, vivemos uma fase de desconfiança em relação aos ditos que são amplamente difundidos pela mídia. Casos de corrupção nas mais diversas esferas da sociedade, reformas trabalhistas, educacionais, bem como informações internacionais, nos surgem através da mídia com diversas nuanças. Mas, quando estes fatos interpretados/editados pelos jornais, entram em contradição com os posicionamentos ideológicos dos sujeitos (leitores, ouvintes, telespectadores), temos um cenário propício para o que Bakhtin chama de "arena". É o que se observa, de forma mais incisiva, nas redes sociais, que hoje configuram um "Quinto poder", um amplo espaço de circulação dos saberes. Na tentativa de fugir das redes convencionais (empresas de comunicação monopolizadoras), os leitores comentam as informações, deixando ao longo do discurso marcas identitárias.

Nas redes sociais os sujeitos, ao sentirem certa liberdade ${ }^{1}$, desfrutam a oportunidade de criticar as notícias, sobretudo de ordem política. Assim, são postos em jogo os princípios que edificam o dizer midiático: credibilidade da informação; neutralidade/imparcialidade; prestação de serviços; princípios éticos e morais. Primando pela instantaneidade do dizer, os meios de informação, em suas mais variadas versões, procuram estabelecer uma relação mais próxima entre os fatos e o público. As notícias em "tempo real" (cobertura de uma eleição, por exemplo) objetivam criar um efeito de verdade e credibilidade, mesmo que no interdiscurso encontremos traços de parcialidade do dizer.

Sobre a questão da temporalidade midiática e suas consequências quanto ao caráter da imparcialidade, a jornalista Moretzsohn (2012, p. 120-121), com base nos estudos marxistas, concebe a velocidade do "tempo real", imposta no jornalismo, como um "fetiche", quando a notícia se torna um mero produto de consumo - uma economia entre a oferta e a procura. Ela afirma que, "com base neste 'fetiche', 'chegar na frente' tornase mais importante do que 'dizer a verdade': a estrutura industrial da empresa jornalística está montada para atender a essa lógica."

E continuando a discussão sobre os dispositivos articulados no ato de informar, Charaudeau (2006) traz uma interessante análise sobre o comportamento das emissoras americanas na cobertura dos ataques terroristas do 11 de Setembro. O pesquisador observa que os jornais utilizaram um jogo de similitudes, típicas de uma roteirização

\footnotetext{
${ }^{1}$ Contudo, sabemos que somos constantemente vigiados, e nas redes sociais não é diferente. A internet possui também códigos e leis que regulamentam os conteúdos que são veiculados. Há todo um trabalho de investigação altamente sofisticado, capaz de detectar crimes da internet. Mesmo com a sensação de anonimato, que propicia uma certa liberdade do dizer, o usuário vai deixando pistas que podem ser rastreadas. Crimes de diversas naturezas foram solucionados graças ao trabalho de especialistas que estão também, diariamente, buscando atualização dos mecanismos investigativos devido à rapidez tecnológica.
} 
televisiva e técnicas cinematográficas. Lá estão: a situação inicial, demarcada no período antes dos ataques, as primeiras horas que antecedem a queda dos aviões; o surgimento dos fatos, o momento exato em que os aviões atingem as torres, cujas imagens aparecem em tempo real, ao vivo, inicialmente por câmeras amadoras, depois por aparelhos tecnológicos oficiais, profissionais; as vítimas, que foram contabilizadas de forma abstrata, mas nota-se que houve preocupação em preservar a imagem dos corpos; as testemunhas, sujeitos que contam o que aconteceu e são vistos como pessoas indefesas. Há, também, os salvadores, bombeiros e outros personagens dessa história, que se empenharam no salvamento das vítimas. E por fim, aquele que Charaudeau denomina $O$ grande salvador - o prefeito de Nova Iorque conclamando a população para a guerra contra o terrorismo, que adquire uma identidade de vingador, e reproduz o discurso do presidente George W. Bush.

Os telejornais brasileiros assumiram também "seu lado" diante dos atentados. Ao mesmo tempo em que mostravam a queda das torres, apresentavam, logo em seguida, a euforia dos palestinos, queimando bandeiras americanas em comemoração aos ataques. Dissemina-se, pois, uma verdade para a população em relação aos jogos de oposições discriminatórias que elegeram o vilão e o mocinho deste "filme".

A influência exercida pela mídia é perceptível nas discussões políticas. Os argumentos utilizados pelos sujeitos comuns ressurgem das informações e comentários proferidos por especialistas formadores de opinião. Todavia, enquanto pesquisadores do discurso e seus efeitos de sentido, devemos sempre procurar aprimorar nosso olhar para a historicidade das coisas ditas e para as condições em que tais enunciados são produzidos, pois quem fala, fala sempre a partir de um lugar e posição na instância social, e "por mais que se diga o que se vê, o que se vê jamais se aloja no que se diz." (FOUCAULT, 2002, p.12).

Mesmo em uma matéria aparentemente neutra, há fortes grupos que "ditam" a tonalidade do dizer jornalístico, muito embora os próprios manuais de cada veículo insistam em afirmar que tal prática não é aceitável. Um aspecto fundamental que não se deve negligenciar na análise do discurso midiático é a questão publicitária. Sabemos que as mídias sobrevivem em função de seus anunciantes - os patrocinadores de cada empresa. A publicidade aparece em vários espaços sociais e são fundamentais para manter uma empresa viva, atuante no mercado.

O discurso publicitário - cujo objetivo é o lucro - atua no inconsciente dos potenciais consumidores, criando a necessidade de consumo. Quem, muitas vezes, não parou em frente a uma loja, guiado(a) pela propaganda de tal produto? Quantas vezes compramos algo de que não estávamos precisando, levados(as) apenas pelos argumentos de um(a) bom/boa vendedor(a) ou porque viu a publicidade na TV? Estudando seu público-alvo, com base em pesquisas e inúmeras técnicas de sondagem, é possível construir uma linguagem costurada de enunciados de efeito e estratégias de repetição. É a velha retórica cada vez mais atualizada.

Slogans como: Compre Baton! Compre Baton! Seu filho merece Baton!, Não esqueça a minha Caloi!, Beba Coca-Cola! resistem ao tempo e ao esquecimento, pois, embora tenham surgindo décadas atrás, ainda continuam vivas nas lembranças de muitas pessoas, provando, assim, a velha máxima de que "A propaganda é a arma do negócio". 
Fundamentado em princípios filosóficos, com base na retórica - arte de convencimento , cria-se um efeito de sentido firmado no desejo, na necessidade de consumidor e de se representar para o outro. As técnicas/táticas de persuasão são inúmeras, e hoje, com o predomínio da cultura do som, imagem e movimento, os dentes aparecem mais brancos, os cabelos são mais sedosos, a pele ressurge mais aveludada e os cosméticos são apresentados com o objetivo de esconder as marcas do tempo através dos "cremes antiidade". São imagens que contribuem para o discurso da felicidade plena. Temos a sedimentação de ideias que procuram retardar a dor, inibir a tristeza e criar um mundo maravilhoso em que não há espaço para o sofrimento ou a crise existencial. Vemos, desse modo, dispositivos ideológicos que tanto têm alimentado o terreno midiático - uma ideia que vende. E vende bem!

Com o avanço do processo de democratização e o surgimento de discussões, até então silenciadas e tidas como tabus, observamos que estamos em um novo mundo de subjetividades que aparece em constante modificação e propiciando uma série de inquietações. Alguns chamam de "crise de identidades e valores", outros de "um novo mal do século", e há quem defenda a necessidade de decretar uma ordem para uma sociedade que perdeu seu rumo e não consegue mais encontrar o caminho de volta. É impossível não reconhecer que a sociedade passa por profundas e rápidas mudanças, e que tais mudanças têm custado caro e vêm provocando choques e conflitos nos mais diversos setores.

A nova cara da sociedade, sobretudo na conjuntura político-social vivenciada a partir de 2016, vem sendo moldada a partir dos movimentos de luta pela igualdade de direitos, em que são criados espaços e ambientes propícios para discussões que envolvem questões de gênero, raça, religião, posicionamentos político-partidários. E nesta conjuntura, as empresas midiáticas também precisam passar por uma fase de reconfiguração e ações de vigilância. Com base na "Lei de responsabilidade social", uma espécie de compromisso firmado na promoção de princípios e valores que contribuam para a melhoria e bem-estar da sociedade, as empresas estão cada vez mais vigiadas. Os discursos publicitários, por serem monitorados pelo CONAR (Conselho de Autorregulamentação Publicitária), estão constantemente respondendo a processos, conforme as demandas de grupos sociais representativos que se sentem agredidos pela forma como os conteúdos são veiculados.

Há casos, por exemplo, de grandes marcas que foram penalizadas com altíssimas multas por trazerem, em sua publicidade, ideologias racistas, machistas ou posturas discriminatórias de várias naturezas. Primando pela conservação da imagem que lhes confere credibilidade no mercado, e temendo a punição, as empresas vêm investindo pesadamente nos últimos anos (desde 2015), em temas que tratam de diversidade e igualdade de direitos. As reinvindicações feitas ao longo da história voltam como uma potente onda que vai ganhando cada vez mais força nas instâncias sociais. É o que podemos observar na análise de duas propagandas de duas marcas famosas no mercado: o Novo Cruze da Chevrolet - empresa multinacional do campo automotivo - e a Skolors - lançamento de latas da $S k o l$ que representam a cor da pele do brasileiro. Analisemos como as duas empresas entram na nova ordem social para modelar suas imagens perante seu público/consumidor. 


\section{NO (RE)DIZER DA CHEVROLET E SKOL: PROCESSOS IDENTITÁRIOS}

Neste tópico analisaremos os processos identitários instaurados no discurso da Chevrolet e da Skol emoldurados de já ditos materializados em um novo acontecimento. Vejamos, inicialmente, o processo de discursivização utilizado pela Chevrolet para convencer seu potencial consumidor.

\section{1 "NOVO CHEVROLET CRUZE: VOCÊ NA DIREÇÃO DA MUDANÇA"}

A Chevrolet se mantém atuante no país desde 1925 e o Brasil compreende o terceiro maior mercado da empresa no mundo, depois da China e Estados Unidos. Em 2014, foram emplacados aproximadamente 580 mil automóveis. ${ }^{2}$ Os números são significativos, de modo que se exige a manutenção e elevação destes dados. Para tanto, torna-se quase que uma obrigação produzir campanhas publicitárias para manter os valores econômicos. É o que notamos no anúncio do carro Cruze lançado desde o mês de maio de 2017, e foi veiculado através da TV e da internet.

Com duração de 00:01:00 (um minuto), o anúncio do Novo Chevrolet Cruze, que tem como slogan "Novo Chevrolet Cruze Sport 6: Você na direção da mudança", apresenta, já em primeiro plano, pontos turísticos do Rio de Janeiro (Arcos da Lapa, conforme figura 1), vazios e que, posteriormente, são ocupados por pessoas protestando com cartazes (figura 2). Vejamos as duas imagens:

\section{Figuras 1 e 2 - Anúncio do Novo Chevrolet Cruze Sport 6}

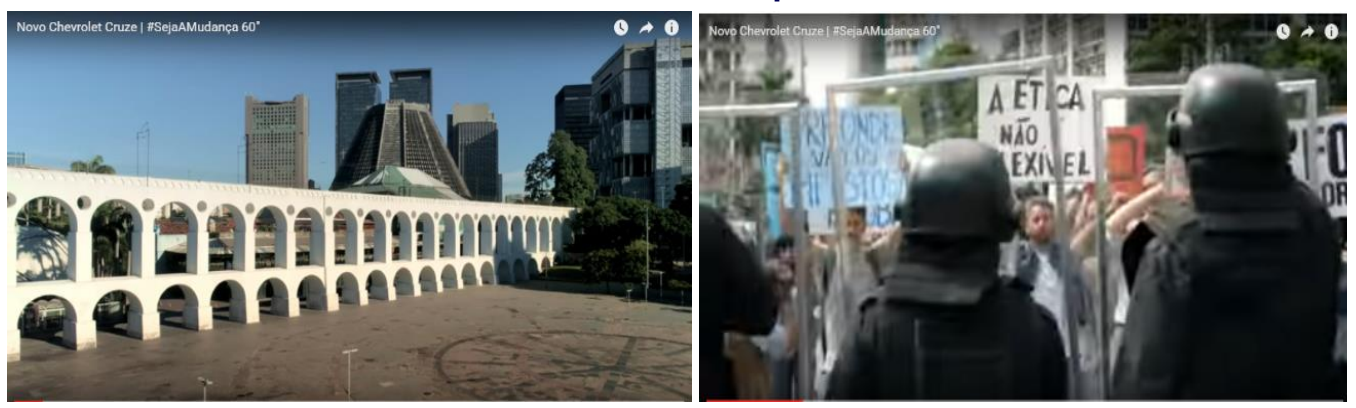

Fonte: http://www.chevrolet.com.br/carros/cruze-sport-6.html

O texto é narrado juntamente com a projeção de imagens da prisão de corruptos e várias ações que envolvem temáticas como respeito e ética, manifestadas em outros espaços sociais: no trabalho, no trânsito, no bar. O texto que é veiculado no site (<www.chevrolet.com.br/carros/cruze-sport-6.html >) é narrado por uma voz feminina e vai surgindo em sincronia com as imagens. Eis o texto na íntegra: 2 Dados fornecidos pelo site: <http://www.chevrolet.com.br/universo-chevrolet/sobre-a-gm/a-
companhia.html> 
Somos um povo que aprendeu a exigir mudanças. E que tá mudando pra servir de exemplo. E que não aceita mais do que é justo. Que cansou da malandragem. Que acelera na direção certa. Somos um povo que aprendeu que sua força vem de cada pessoa. Porque na prática, a mudança começa com você. Novo Chevrolet Cruze: Você na direção da mudança. ${ }^{3}$ (grifos nossos).

A função enunciativa, apresentada nas materialidades do anúncio, dialoga com as características da mídia - instantaneidade e atualidade - emolduradas de uma retórica que conversa diretamente com o público. O calor dos acontecimentos que dominam a atual conjuntura política do país (denúncias e prisões envolvendo casos de corrupção, operações policiais, discussão sobre reafirmação de valores tão esquecidos nas relações interpessoais), é recuperado agora em busca de preservar e modelar a identidade da marca Chevrolet. Seu consumidor é aquele que "quer mudanças" e que "cansou da malandragem". A proposta reside em unir a velocidade das transformações sociais com a velocidade do carro, pois o povo/motorista do carro "acelera na direção certa".

$\mathrm{O}$ texto mostra que houve uma mudança significativa na atitude do brasileiro. Antes visto como um povo passivo, que não reivindicava seus direitos, no momento atual ele está não apenas se posicionando nas redes sociais, mas se deslocando para as ruas. $\mathrm{O}$ "quinto poder" - a influência das redes - aparece no anúncio como uma ferramenta desta resistência. $\mathrm{O}$ deslocamento dos lugares de confronto travados pela população (das redes para as ruas) chega a seu ápice, seu grand finale - com a escolha do carro - o Novo Chevrolet Cruze Sport 6.

Para construir uma positividade, há junção entre imagens, sons e movimentos. A música de fundo determina o ritmo do dizer e também constitui sentido. Até os trinta e quatro segundos (00:00:34), há a predominância do rock, um ritmo mais ácido, forte, com o objetivo de ratificar o movimento - a fúria das pessoas em atitude de protesto. A partir da metade do anúncio (segundos posteriores) até seu final, predomina o samba, que aqui é utilizado estrategicamente no momento em que tais reinvindicações extrapolam os limites da política e ocupam outros fóruns de debate. O ritmo muda e revela em seu interdiscurso, a ideologia do discurso nacionalista que perdura até o surgimento de um casal que antes estava nas ruas, e agora se desloca para a garagem de um prédio e adentra, cada um, em seu Cruze. Os dois modelos (personagens principais do anúncio) figuram este consumidor que está "na direção da mudança". Tudo em uma perfeita sincronia e sinfonia de ideias, movimentos, cores e sons.

A trilha sonora é, deste modo, determinante para a mensagem publicitária da Chevrolet e sustenta o discurso da mudança, pois, como operadora de memória, a mídia contribui para promover valores que comumente não eram apresentados em um anúncio de carro. A mudança está também na nova postura da Chevrolet. A rigor, suas mensagens sempre traziam a ideia de movimento, carros na lama, figuras masculinas vencendo obstáculos para demonstrar a resistência e força do carro. A mudança está em ajustar/afinar/sincronizar tais movimentos com as novas configurações sociais, reproduzir, portanto, efeitos de atualização/modernização/democratização.

\footnotetext{
${ }^{3}$ Fonte: http://www.chevrolet.com.br/carros/cruze-sport-6.html
} 
Ao reatualizar o discurso da mudança, neste novo acontecimento discursivo - a propaganda - a marca se autopromove, apresentando-se como uma empresa séria, atual, que está em parceria com a sociedade, sustentando o discurso do engajamento político, democrático e participativo. Assim, preserva seu potencial de mercado - o lucro - e constrói novas subjetividades: uma empresa que não tem preconceitos, que está atenta às questões políticas e que não aceita a corrupção. Vai, portanto, ganhando cada vez mais espaço no cenário automotivo e midiático. A empresa segue estratégias semelhantes a outras empresas que estão "cantando" a mesma música - o discurso da transformação social. É o que faz também a Skol.

\subsection{A SKOL CORES E O DISCURSO DA DIVERSIDADE}

De origem dinamarquesa com licença para ser produzida no Brasil, a Skol (que significa à vossa saúdelà nossa saúde - uma saudação escandinava) sempre gerou polêmica por causa dos anúncios que comumente, a exemplo de outras marcas de cerveja, trazem mulheres seminuas para apresentar o produto. Os textos aparecem com duplo sentido que dialogam diretamente com a silhueta (curvas) da mulher. O slogan "Skol: A cerveja que desce redondo" sempre parecia de modo provocativo e povoava o imaginário masculino, na concepção dos anunciantes. Dentre vários anúncios que traziam discursos machistas e erotização da mulher, vejamos o anúncio produzido alguns anos atrás e que foi alvo de muitas críticas, principalmente advindas do movimento feminista, e que resultaram em uma advertência do CONAR.

\section{Figura 3 - Anúncio da Skol}

Fonte: http://www.ultracurioso.com.br/

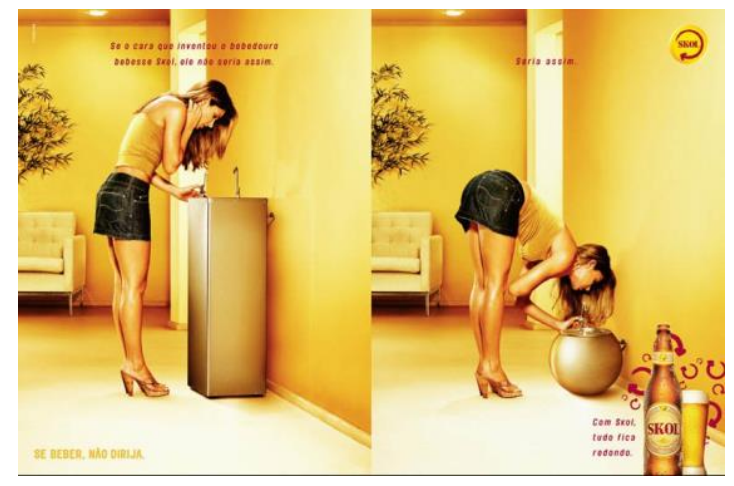

O anúncio (Figura 3) faz parte de uma campanha da Skol que trazia o slogan "Se o cara que inventou o bebedouro bebesse Skol, ele não seria assim. Seria assim". A frase era sempre preenchida com alguma invenção/produto, mas sempre evidenciando a posição da mulher em atitude erótica ou realçando as partes de seu corpo, mais precisamente os seios e os glúteos. Neste anúncio, vemos a imagem de uma mulher em uma posição erótica com o objetivo de despertar o olhar masculino. As cores amarelo, laranja e vermelho, predominantes no texto, dialogam com a cor da cerveja e estimulam o paladar, ou seja, o apetite sexual. São cores quentes e chamativas. 
A Skol sempre foi criticada por trazer em seus anúncios mulheres como objetos sexuais. Até 2016 os anúncios ainda traziam mensagens polissêmicas incorporadas de preconceitos e estereótipos contra a mulher brasileira. Após intensos embates e críticas registradas por grupos feministas e organizações que lutam pela valorização das identidades, observamos uma mudança sutil, embora ainda apareçam discursos machistas em propagandas de cerveja, como é perceptível em marcas como a Itaipava, Devassa, entre outras, que comumente associam a mulher a objeto de satisfação sexual masculina.

Os novos tempos chegam e com eles ressurgem também velhos discursos com uma nova roupagem, e que propiciam discussões que vão se metamorfoseando em outras materialidades, e se cristalizando no discurso da mídia. Bauman (2005, p.19) defende que as identidades são líquidas, pois se adequam aos espaços sociais. Para ele "as identidades flutuam no ar, algumas de nossa própria escolha, mas outras infladas e lançadas pelas pessoas em nossa volta, e é preciso estar em alerta constante para defender as primeiras em relação às últimas". A mudança de estratégia orquestrada pela Skol dialoga com a teoria de Bauman. Articulam-se novas identidades que vão se adequando às novas exigências de uma sociedade mais democratizada e politizada, mas em constante vigilância. Temos um mercado cada dia mais exigente.

De modo semelhante aos procedimentos ideológicos e discursivos da Chevrolet, observamos que a $\mathrm{Skol}$ segue o compasso das empresas atuais: retomar o princípio da mudança social, mas agora focalizando o discurso da diversidade, através de uma série especial de latas com as cores da pele - denominada Skolors - um neologismo criado para lançar um novo produto e construir um jogo de similitudes com os questionamentos atuais - defesa dos direitos, reafirmação da identidade nacional, e, sobretudo, luta pela valorização da diversidade em suas múltiplas tipologias.

Sabemos que a luta pela igualdade de direitos dominou a sociedade em várias épocas e vigora nos dias atuais. O processo de formação do povo brasileiro, não muito diferente do que ocorre em outros países, é dominado por histórias que trazem, em suas entrelinhas, episódios de tortura e extrema exclusão de pessoas que eram consideradas "diferentes" por causa da cor de sua pele ou de sua língua. O regime escravocrata que dominou nosso país até maio de 1888 , testifica um mecanismo de segregação do indivíduo em seu grau mais extremo. Se hoje ainda discutimos estas questões, ou se necessitamos de leis que possam dirimir o preconceito racial, por exemplo, é porque não vislumbramos essa "libertação da escravatura" como está cristalizado nos livros didáticos de história.

O caráter de originalidade da campanha da Skol está em conseguir recuperar enunciados em circulação na esfera social e dar a eles consistência de novo. O anúncio não fala mais sobre os protestos nas ruas, ou denúncias dos casos de corrupção, e não temos aqui a predominância explícita do discurso da ética e moral, conforme fez a Chevrolet. A Skol projeta seus holofotes ideológicos para a política da diversidade de gênero, de raça, de idade, de corpo, de beleza, de cultura, entre tantas outras diferenças que devem nos unir e não nos segregar. Temos dizeres velhos com outra formulação que produz sentidos em um outro acontecimento. Seus enunciados ressurgem povoados de outros enunciados: voltamos para o período colonial, passamos pelo movimento de segregação nos Estados Unidos, o genocídio da segunda guerra mundial, em que se defendia uma raça pura, e que ressurge agora em forma de negatividade e fomentando movimentos de resistência. 
Considerada como uma marca de cerveja que sempre reproduzia discursos machistas por tratar a mulher de modo pejorativo, como vimos, a Skol procura silenciar seu passado e se aproximar da figura feminina, instaurando, assim, uma positividade. Aposta neste "novo discurso" para atingir um maior número de consumidores, utilizando a internet e incorporando uma atualização dos ditos quando une imagem, som e movimento. A página online da Skol (<http://www.skol.com.br/verao/>) evidencia, já em primeiro plano (na capa), sua nova campanha, que tem como slogan "Skolors: uma edição especial de latas nas cores da nossa pele", apresentada num filme publicitário com duração de um minuto e vinte e dois segundos - (00:01:22). Sabemos que o minuto da TV exige muitos custos, assim, a empresa procurou utilizar seu espaço próprio, seu site, para se vender e se autopromover. Vejamos como suas estratégias são discursivizadas a partir das duas imagens (figuras 4 e 5) que representam duas cenas do filme:

\section{Figuras 4 e 5 - Cenas da campanha Skolors}

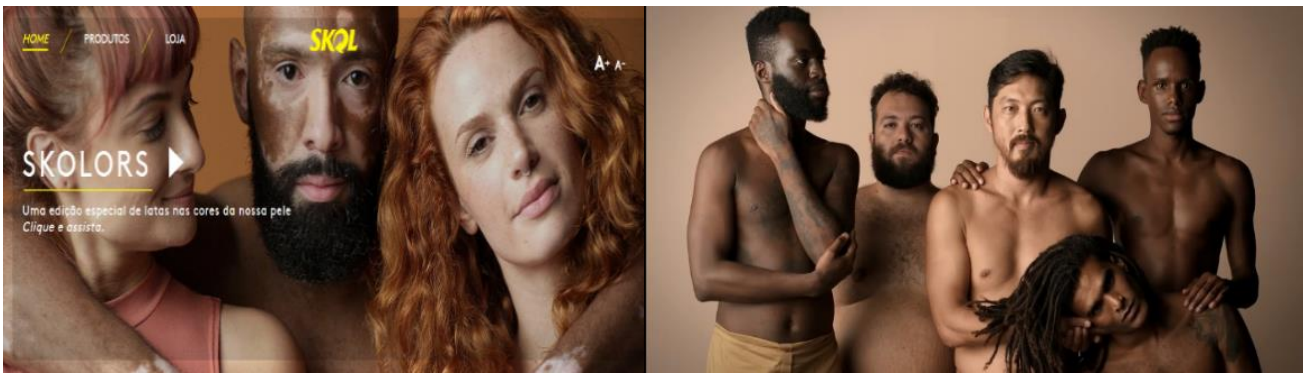

Fonte: http://www.skol.com.br/verao/

A interação com o internauta é cuidadosamente pensada. A partir do primeiro momento, o leitor/consumidor, além de poder navegar pelas páginas da campanha, pode também observar três pessoas diferentes quanto à cor da pele e gênero: duas moças ruivas e um rapaz que traz na pele sintomas do vitiligo (anomalia na pele e que é atestada por muitas pessoas) e é posicionado ao centro, entre as duas mulheres.

O vídeo começa com uma música de fundo (som de batuque e berimbau, que reproduz o ritmo africano mesclado com o samba) e a imagem de uma mulher branca de costas, sendo abraçada por uma mulher negra, que traz em uma de suas mãos a cerveja de cor marrom e dirige-se para a câmera. O caráter de originalidade da campanha está em conseguir recuperar enunciados em circulação na esfera social e construir um efeito de atualidade. Durante todo o filme são apresentadas pessoas de várias cores, raças, idades e formas físicas se abraçando, mas sempre projetadas para as lentes da câmera e trazendo, em suas mãos, as latas coloridas, que dialogam com a cor da pele dos personagens. Há um diálogo também com a cor da parede de fundo que aparece com a mesma tonalidade, e assim entra em harmonia com a proposta da campanha fomentar o discurso da diversidade.

A segunda imagem dita também a regularidade do (re)dizer. São apresentados cinco homens diferentes quanto à raça e estrutura corporal, mas que estão próximos, são postos em uma relação cordial. O filme apresenta cortes de imagens que focalizam detalhadamente partes dos corpos dos sujeitos em evidência: a boca, as mãos, os pés, o tórax, os cabelos, os olhos. São utilizados, ainda, jogos de montagem das imagens dos modelos para construir um efeito de unidade (conforme a figura 6). E a última imagem 
(figura 7) traz as latas de cerveja com o slogan que domina o discurso atual: "Skol: redondo é sair do seu quadrado". O jogo de similitudes com o enunciado "redondo" é materializado no movimento giratório das latinhas. Este efeito circular não apenas recupera seu slogan antigo "A cerveja que desce redondo", mas aparece para evidenciar a mudança e transformação da sociedade. As cores das latinhas interdiscursam com as pessoas do anúncio e rememoram o povo brasileiro, sedimentando a ideia de uma só nação.

Figuras 6 e 7 - Cenas da campanha Skolors

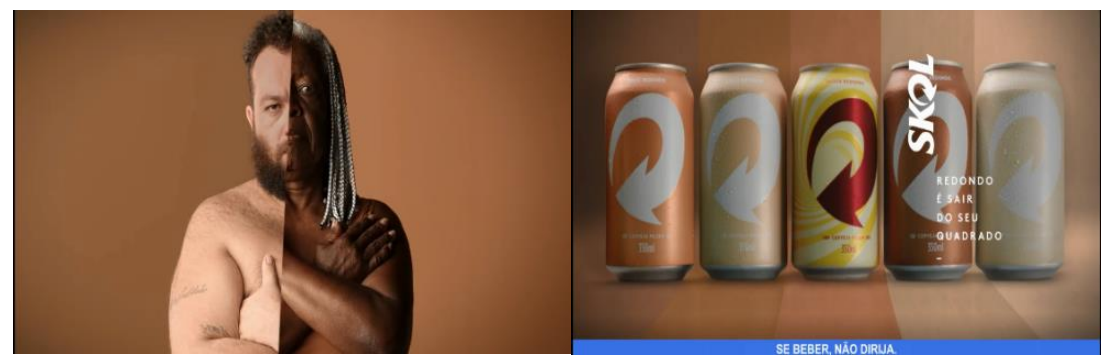

Fonte: http://www.skol.com.br/verao/

A empresa atende às demandas sociais, como fazem outras empresas, e se encaixa neste novo movimento de reafirmação nacional, trazendo um discurso engajado na política de valorização da diversidade em seus mais distintos aspectos. Se representa com a ideia de unidade, conforme vemos nas figuras 6 e 7, com um arrojado processo de montagem e efeitos de imagem, partes de fotos de dois sujeitos completamente diferentes fisicamente: um homem branco e uma mulher negra - ambos seminus. São distintos fisicamente, mas são brasileiros, e é isto que os une. A identidade é formada através deste mosaico de várias identidades, e é nesta diferença que reside a riqueza cultural do povo brasileiro, em não ser considerado como uma homogeneidade e posto de modo fechado e fixo, pois "redondo é sair de seu quadrado", uma frase que dialoga com o dizer de Bauman (2005, p. 35), quando defende que "em nossa época líquido-moderna, em que o indivíduo livremente flutuante, desimpedido, é o herói popular, 'estar-fixo' - ser 'identificado' de modo inflexível e sem alternativa - é algo cada vez mais malvisto."

A dinamicidade e incessante mutação flutuante são características perseguidas e defendidas no discurso midiático. Há sempre necessidade em inovar, procurar algo diferente das estratégias de outras empresas. $\mathrm{O}$ mercado cada vez mais competitivo e exigente, como é o universo midiático, exige que os anúncios tragam sempre algo original e que esteja à frente de seu concorrente - o que importa é fazer a diferença. Como o discurso "politicamente correto" está "na moda" e vem crescendo cada dia mais a partir dos primeiros meses de 2017, a Skol almeja fazer a diferença construindo estratégias para se representar/reafirmar/subjetivar perante o público brasileiro, trazendo a discursivização sobre a diversidade e a revalorização da nacionalidade.

Com este discurso a Skol recupera a confiança perante o público, principalmente o feminino, no sentido de ganhar notoriedade. Não há mais espaço aqui para o questionamento da sexualidade, ou a erotização da mulher projetada de modo pejorativo. Há, com esta estratégia, uma reconstrução de valores esquecidos e silenciados. Quando evidencia a diversidade racial e posiciona os negros como protagonistas do filme, se vende como empresa séria, comprometida com o exercício de democratização e 
valorização da cultura brasileira. Esta é a fórmula encontrada e assumida pela Skol para ganhar credibilidade e, consequentemente, gerar lucro e se manter ativa no ramo de bebidas, um mercado altamente competitivo.

\section{CONSIDERAÇÕES FINAIS}

Nossa análise nos convida para uma reflexão de como os elementos sociais, históricos e ideológicos produzem saberes e estabelecem jogos disciplinares no universo midiático. A Chevrolet e a Skol, empresas já consolidadas no mercado, uma no ramo automotivo e outra no ramo de bebidas, estão atentas aos novos posicionamentos da sociedade e procuraram projetar suas imagens a partir dos discursos atuais.

Os pressupostos epistemológicos da Análise do Discurso e o diálogos com outras perspectivas teóricas, nos forneceram pistas para investigar, no interior dos discursos, o jogo da memória e os mecanismos de poder e disciplinamento, buscando entender, portanto, como os sujeitos exercitam seu direito através das resistências. A tentativa de atualização do discurso da autoafirmação nacional e valorização da identidade, demonstra o empoderamento da sociedade que quer mudança e que luta por isso a ponto de não aceitar mais ideias excludentes e preconceituosas.

Mesmo procurando sincronizar as novas exigências da sociedade - a Chevrolet com o resgate de valores como ética, moral e construção de uma consciência política e a Skol com o discurso da diversidade como valorização identitária -, entendemos que as empresas respondem por lugares de consumo, cujos objetivos estão pautados no lucro, na geração de renda - o que, a rigor, não poderia ser diferente. Contudo, embora encontremos nuanças do discurso capitalista, não podemos deixar de reconhecer que os procedimentos midiáticos apresentados nos dois anúncios já configuram resultados positivos imbricados na luta para dirimir o abismo cultural entre os indivíduos.

Entendemos, enfim, que devemos adotar certa cautela em valorizar tais enunciados como verdades absolutas, mas é importante reconhecer, a partir destes textos, que as minorias (sujeitos silenciados ao longo da história) saíram de um regime de extrema clausura e cerceamento, para ocuparem espaços que até então eram destinados aos homens brancos e de maior poder aquisitivo na sociedade. São as novas configurações identitárias que estão ganhando outros contornos na mídia brasileira. E não podemos deixar de reconhecer.

\section{REFERÊNCIAS}

BAKHTIN, M. Estética da criação verbal. 3. ed. São Paulo: Martins Fontes, 2000.

BAUMAN, Z. Identidade: entrevista a Benedetto Vecchi. Rio de Janeiro: Zahar, 2005.

CHARAUDEAU, P. Discurso das mídias. São Paulo: Contexto, 2006.

FOUCAULT, M. A ordem do discurso. 6. ed. São Paulo: Edições Loyola, 2000.

. As palavras e as coisas. 8. ed. São Paulo, Marins Fontes, 2002.

Microfísica do poder. 21. ed. Rio de Janeiro, Edições Graal, 2005.

MORETZSOHN, S. Jornalismo em "tempo real": O fetiche da velocidade. 2. ed. Rio de Janeiro: Revan: 2002.

PÊCHEUX, M. O discurso: Estrutura ou acontecimento. 2. ed. Campinas, Pontes, 2006. 
Anúncio do Novo Chevrolet Cruze Sport 6: Disponível em: <http://www.chevrolet.com.br/carros/cruzesport-6.html>. Acesso em: 10 abr. 2017.

Anúncio da Skol: Disponível em: <http://www.ultracurioso.com.br/6-propagandas-de-cerveja-quecausaram-maior-confusao/>. Acesso em: 10 abr. 2017.

Anúncio da Skol Cores: Disponível em: 〈http://www.skol.com.br/verao/>. Acesso em: 10 abr. 2017.

\section{Recebido em: 13/04/17. Aprovado em: 15/09/17.}

Title: New configurations of identity and its effects of sense in Brazilian media

Author: Edjane Gomes de Assis

Abstract: Based on the French discourse analysis, especially in the wake of Pêcheux (2006), Foucault (2000; 2002; 2005), Charaudeau (2006), and in dialogue with the Dialogical Discourse Analysis (BAKHTIN, 2000), and sociological reflections by Bauman (2005) still establishing a liaison with the communication theory (MORETZSOHN, 2012), our study examine how the current discourse about the reaffirmation of national identity and their new settings, resurface in Brazilian media through disciplining mechanisms of the reader/consumer. Thereunto, we analyze two companies' advertises, Chevrolet and Skol, both broadcasted in March 2017. Understanding the text advertising as a discursive, materiality in which are interwoven social, historical and ideological elements, showed that the two campaigns, in order to (re) claim before the society, recover the democratization discourse from the new social demands, but in your interdiscursivity prevails the idea of selfpromotion, whose main objective is profit. Then presume a characteristic positioning of a capitalist and competitive society.

Keywords: Discourse. Identity. Brazilian media.

Título: Nuevas configuraciones de identidade y sus efectos de sentido en la media brasileña Autora: Edjane Gomes de Assis

Resumen: Basado en el Análisis del Discurso francesa, sobretodo en la estera de Pêcheux (2006), Foucault (2000; 2002; 2005) y Charaudeau (2006), y en diálogo con el Análisis Dialógico del Discurso (BAKHTIN, 2000), con las reflexiones sociológicas de Bauman (2005), aún estableciendo articulación con la Teoría de la Comunicación (MORETZSOHN, 2012), nuestro estudio investiga cómo los discursos actuales sobre la reafirmación de la identidad nacional y sus nuevas configuraciones resurgen en la media brasileña a través de mecanismos disciplinares. Para ello, analizamos dos campañas publicitarias de las empresas Chevrolet y Skol, las dos transmitidas en marzo de 2017. Comprendiendo el texto publicitario como materialidad discursiva, en el que están imbricados elementos sociales, históricos e ideológicos, evidenciamos que las campañas, para (re)afirmaren delante de la sociedad, recuperan el discurso de la democratización proveniente de las nuevas demandas sociales, pero en su carácter inter discurso prevalece la idea de autopromoción, cuyo objetivo mayor es el ingreso. Asumen, así, posicionamientos característicos de una sociedad capitalista y competitiva.

Palabras-clave: Discurso. Identidad. Media brasileña.

Este texto está licenciado com uma Licença Creative Commons Atribuição 4.0 Internacional. 